\title{
Epidemiology of physician interventions in maritime environment by the Marseille Fire Brigade (BMPM) from 2005 to 2017
}

\author{
Jean-Paul Boudsocq, Guillaume Bellec, Coralie Gueho, Hugo Lenglet, Franck Peduzzi \\ The Marseille Fire Brigade, Marseille, France \\ Bataillon de marins pompiers de Marseille (BMPM), Marseille, France
}

\begin{abstract}
Background: Marseille is the second largest city in France. The Marseille Fire Brigade (BMPM) is the largest unity of the French Navy. This organization is in charge of rescue operations and medical intervention in the Marseille area. The aim of the study was to describe the epidemiology of interventions that required a physician to be present that were performed by the BMPM between the years of 2005 to 2017.

Materials and methods: The statistical office database of the BMPM and the medical interventions forms (FIM) acquired from the BMPM medical ambulances (SMUR) archives were analysed from the years 2005 to 2017. Results: The BMPM performed a total of 2,375 interventions in the maritime environment between 2005 and 2017. A physician was necessary for intervention a total of 186 times. The extraction and analysis reports of 107 medical intervention forms found the BMPM archives revealed a significant number of interventions (67\%) in the southern bay of Marseille and Frioul, specifically from the If and Planier islands. The majority of interventions (77\%) took place within the $300 \mathrm{~m}$ band. The most common cause of medical intervention was due to an accidental fall into the water, followed by boating (sailing and motor), and swimming. Drowning was the most common cause of mortality, consisting of $34 \%$ of all interventions. Diving accidents represented $14 \%$ of interventions. Trauma affected $22 \%$ of the study population and $83 \%$ of trauma patients were transported to the hospital under the supervision of a physician.

Conclusions: Potential areas for improvement in the management of drowning victims are the use of Szpilman's classification, sonography, and non-invasive ventilation. A recertification course for medical education training of BMPM doctors on the management of diving accidents could help to optimize the information recorded on FIM. Accident prevention training should be continued and reinforced when it comes to maritime activities.
\end{abstract}

(Int Marit Health 2019; 70, 3: 158-166)

Key words: firefighters, drowning, diving, emergency service, first aid, naval medicine

\section{INTRODUCTION}

Marseille is the second largest city in France. Its commercial and cruise ports are the largest in France and are among the largest in Europe (2.5 million passengers including 1.5 million cruise passengers per year). Its seafront, compromising $57 \mathrm{~km}$, includes 14 ports, 21 islands, dozens of beaches, and $20 \mathrm{~km}$ of creeks. Significant fishing activity is reported with 138 vessels. Many leisure activities are organized in Marseille: 100 diving sites can exceed $50 \mathrm{~m}$ in depth and as many as 200 regattas are held annually.
The city is currently planning to host the sailing competition for the 2024 Summer Olympic Games.

The Marseille Fire Brigade (BMPM) is the largest unit in the French Navy. It is under the direct authority of the mayor and is subject to civil security regulations. The battalion provides an average of 120,000 annual interventions, $81 \%$ of which are for the relief of people. Some of these interventions can be performed by the physician of one of the 3 medical ambulances (SMUR) of the fire brigades (Plombières, Endoume and Louvain) at the request of the Bouches-du-Rhône Emergency

Dr. Jean-Paul Boudsocq, Bataillon de marins pompiers de Marseille, 9 boulevard de Strasbourg, 13233 Marseille Cedex 20, France, tel: +33 648398005 ,

e-mail: jeanpaul.boudsocq@gmail.com 
Medical Service (SAMU 13). Medical support for firefighters in interventions is provided by the medical support vehicle(VMS).

Some platoons of the battalion have a specific focus on the maritime environment. The aquatic section (SOS AQUA) has 158 personnel, including 36 divers and 13 boats. The helicopter section (SOS HELI) allows firefighters to be deployed by helicopter for operations at sea. The depollution section (SOS DEPOL) ensures among its missions, the protection of the coastline and sensitive sites and the recovery of pollutants. The Fire and Survival Techniques Training Centre (CETIS) is in charge of shipboard response training (IBN), survival in extreme environments, and survival at sea. Since 2016, the capacity to respond to disasters on board ships (CAPINAV) has been the means of zonal and national reinforcement to ensure the coverage of a large-scale maritime rescue in French territorial waters. The Maritime Medical Response Unit (UMIMM) is an integral part of CAPINAV.

Despite this important sea-based rescue structure, there is no study describing the marine interventions carried out by the BMPM. The purpose of the study was to establish the epidemiological characteristics of interventions with a physician in the maritime environment by the BMPM between the years of 2005 to 2017.

\section{MATERIALS AND METHODS}

\section{TYPE OF STUDY}

Monocentric retrospective descriptive analysis.

\section{PARTICIPANTS, INCLUSIONS AND DATA COLLECTION}

\section{Global data on BMPM maritime interventions}

The statistical office of the BMPM is in charge of analysing data from BMPM interventions. The information is collected by means of a standardized questionnaire at the Marseille Fire and Rescue Services Operational Centre (COSSIM) and by standardized ambulance intervention reports. This office provided the following data: mission number, date, type of intervention, place of intervention, type of vehicle and connecting base.

\section{Data on interventions with a doctor}

For each patient, the doctor wrote a medical intervention form (FIM) on paper format and since 2016 in computer format. The FIM were extracted from the archives and database of the T-SMUR $^{\circledR}$ software (GIP e-SANTE ORUPACA ${ }^{\circledR}$, Hyères, France). Demographic, environmental, and medical data related to the intervention were manually entered into a specific table.

\section{STATISTICAL ANALYSIS OF THE RESULTS}

The statistical analysis of the study data was performed using Excel ${ }^{\circledR} 2010$ software (Microsoft Corporation, Redmond, USA). Quantitative variables were described by mean and confidence intervals and qualitative variables by frequency and percentage.

\section{RESULTS}

\section{GENERAL DATA ON BMPM MARINE RESPONSE}

The BMPM carried out 2,375 marine interventions between 2005 and 2017 involving 4,644 vehicles. The annual average of interventions was 183 ( $\mathrm{Cl} 95: 180.04 ; 185.96)$ $(\min =101, \max =362)$ (Fig. 1).

The majority of maritime interventions took place in the summer season (from June to September) with a total of 1,434 interventions over the period 2005 to 2017 compared to 941 from October to May.

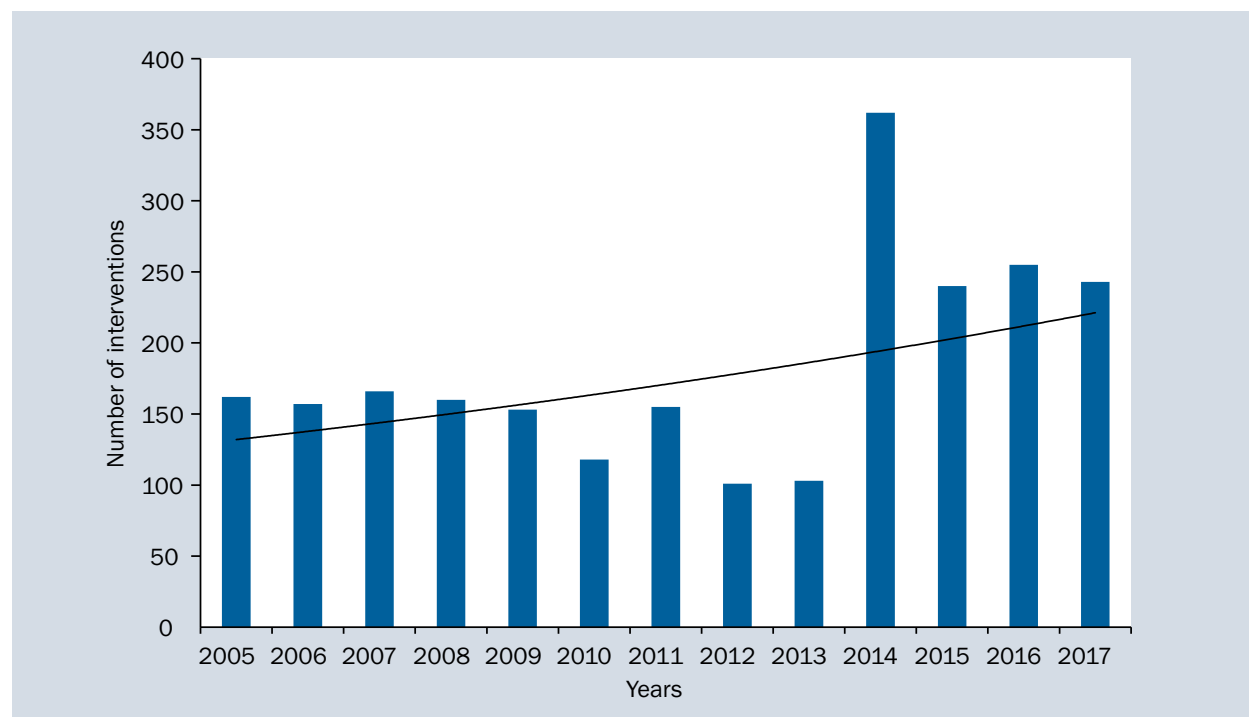

Figure 1. Annual distribution of BMPM maritime interventions 


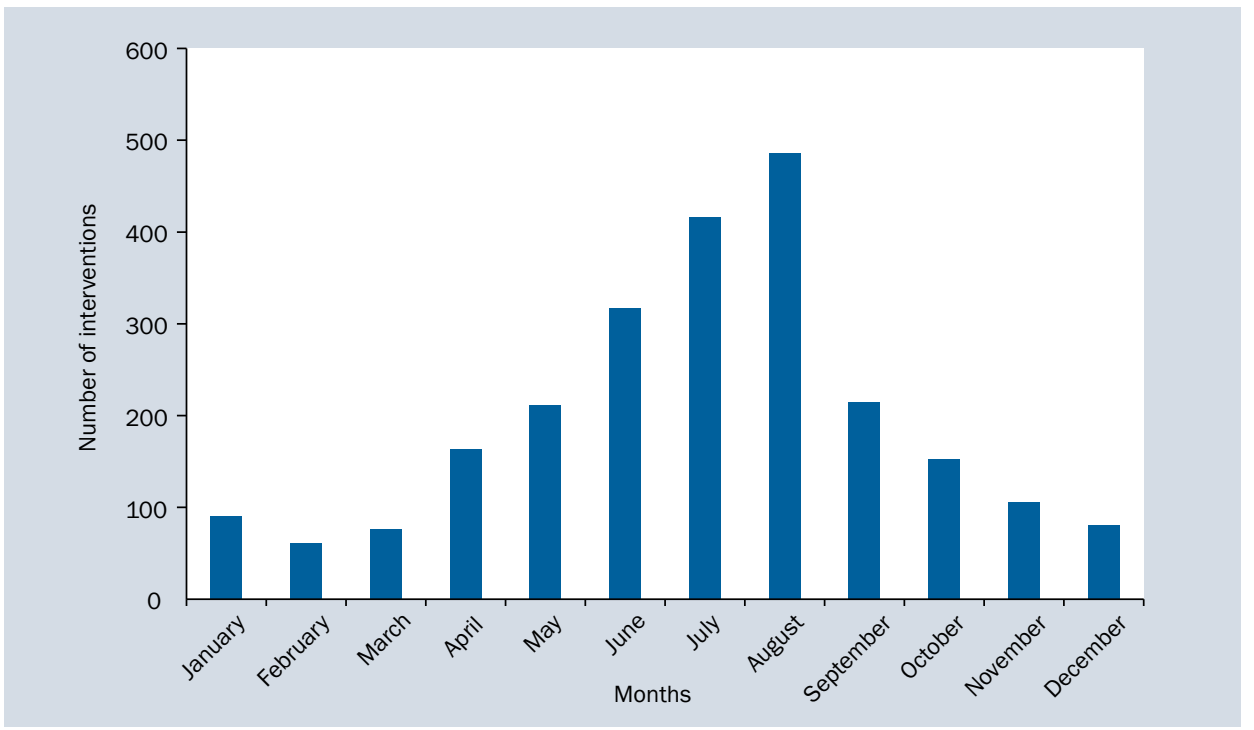

Figure 2. Monthly cumulative of the BMPM maritime interventions

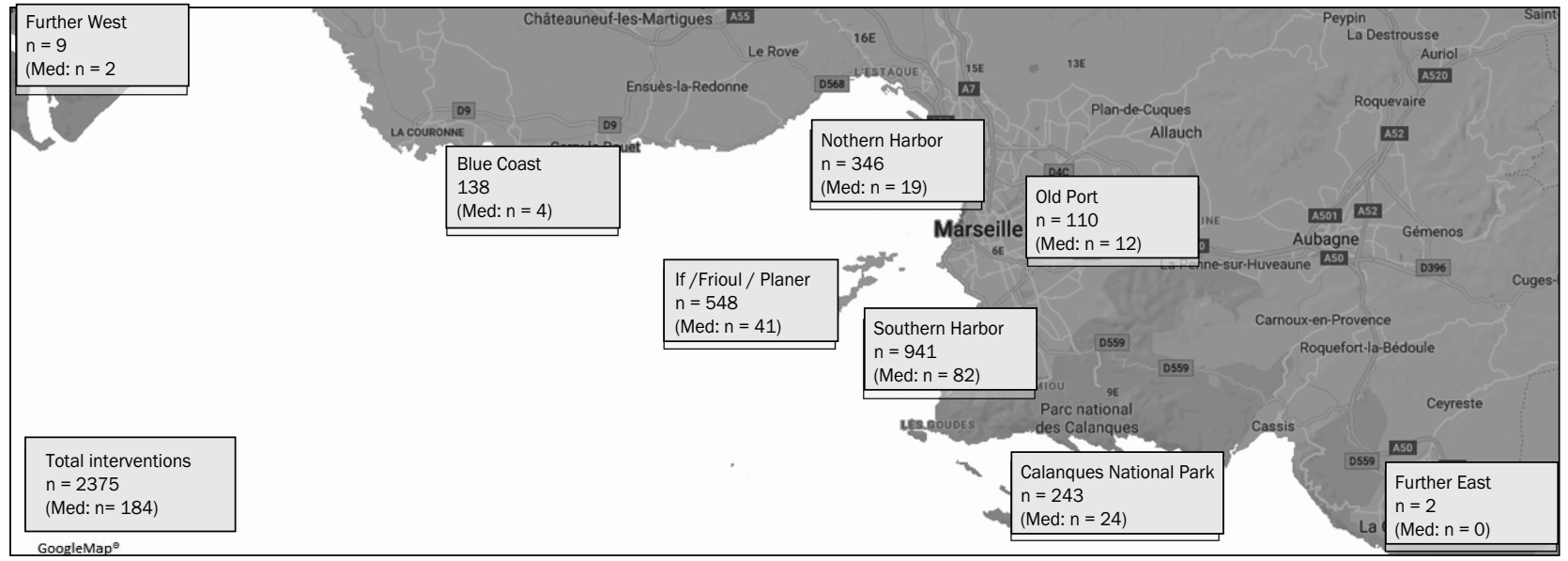

Figure 3. Geographical distribution of BMPM interventions

July and August were the most active months (902 interventions) with a peak of 486 cumulative interventions in August (Fig. 2).

The coast, the southern harbour of Marseille and the If, Frioul and Planier islands accounted for $64 \%$ of BMPM's maritime interventions (Fig. 3).

\section{INTERVENTIONS INVOLVING A DOCTOR}

\section{General information}

The BMPM referred 186 interventions to a physician between 2005 and 2017, involving 215 medical vehicles. The most frequent medical vehicles involved were the VMS $(n=63)$, the SMUR Louvain $(n=56)$, and the SMUR Endoume $(n=36)$.

The average annual number of interventions with a doctor was $14(\mathrm{Cl} 95: 13.12 ; 14.88)(\min =8, \max =28)($ Fig. 4).
The majority of these interventions took place during the summer season (from June to September) with a total of 110 interventions over the period 2005 to 2017, compared to 76 from October to May. August was the busiest month with 41 interventions (Fig. 5). The coast, the southern harbour of Marseille and the islands If, Frioul and Planier concentrate $67 \%$ of interventions requiring a doctor (Fig. 3).

As a result of searches in the BMPM SMUR database, 59 interventions were not related to patient management (ship in difficulty, operational medical support, cancelled outings, etc.) and $20 \mathrm{FIM}$ were not found at the time of data collection. A total of 107 FIM were analysed. Regarding the location, $98 \%$ of the interventions took place in the municipality of Marseille and $2 \%$ in the municipality of Cassis. The gender distribution was $64 \%$ male, $32 \%$ female, and $4 \%$ unspecified. 


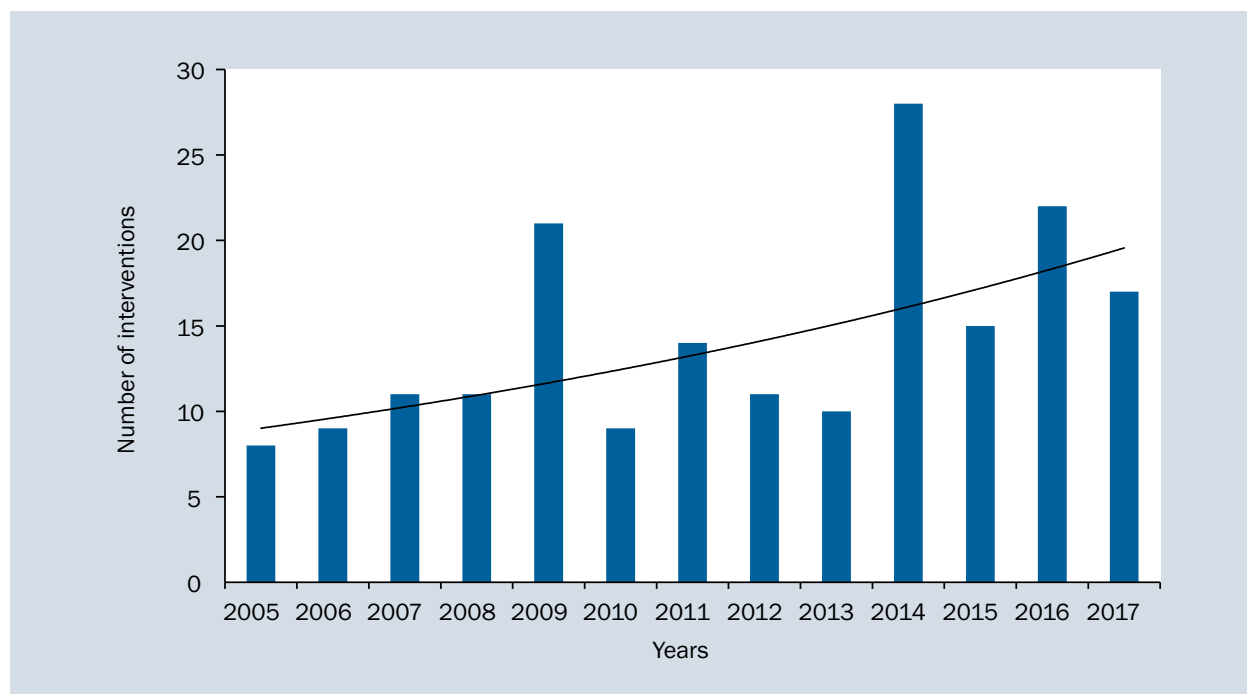

Figure 4. Annual distribution of BMPM medical maritime interventions

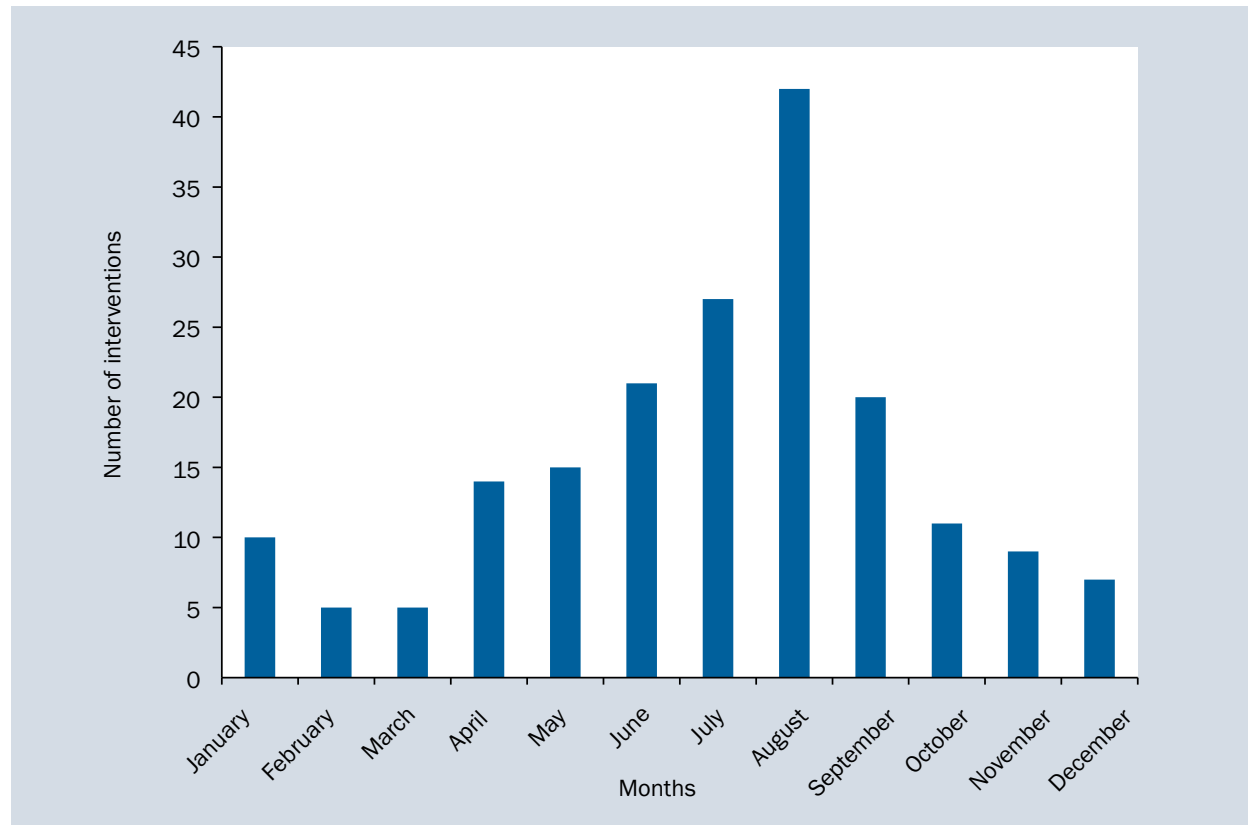

Figure 5. Monthly cumulative of the BMPM medical maritime interventions

Out of 98 interventions specifying the age of patients, the average age was 42 years ( $\mathrm{Cl} 95: 37.8 ; 45.4)$, with a distribution by sex: 46 years (Cl 95: 35.1; 48.9) for women and 39 years $(\mathrm{Cl} 95: 34.8 ; 43.6)$ for men. People in the $25-44$ age group $(n=35)$ were the most represented, followed by people aged $45-64(n=27)$ and those over $65(n=15)$. The 6 -12 age group was the least represented $(n=0)$, followed by the $0-5$ age group $(n=3)$, the $13-19$ age group $(n=8)$ and the 20-24 age group ( $n=8$ ) (Fig. 6).

Out of 88 interventions in terms of geographical location to the coast, $77 \%$ of the interventions took place in the $300 \mathrm{~m}$ band compared to $17 \%$ above $300 \mathrm{~m}$ and $6 \%$ on the coast.

Accidental falls into the water were the most frequent cause of intervention requiring attention by a physician $(n=21)$, followed by boating $(n=17$, motor $=10$, sailing $=7)$, swimming $(n=16)$, and diving accidents $(n=16$, diving $=15$, freediving = 1) (Fig. 7).

Based on mission order schedules ( $n=105)$, interventions involving a physician took place during the day (between $10 \mathrm{am}$ to $7 \mathrm{pm}$ ) and sometimes at night, with a peak of 13 interventions at 4 pm (Fig. 8). 


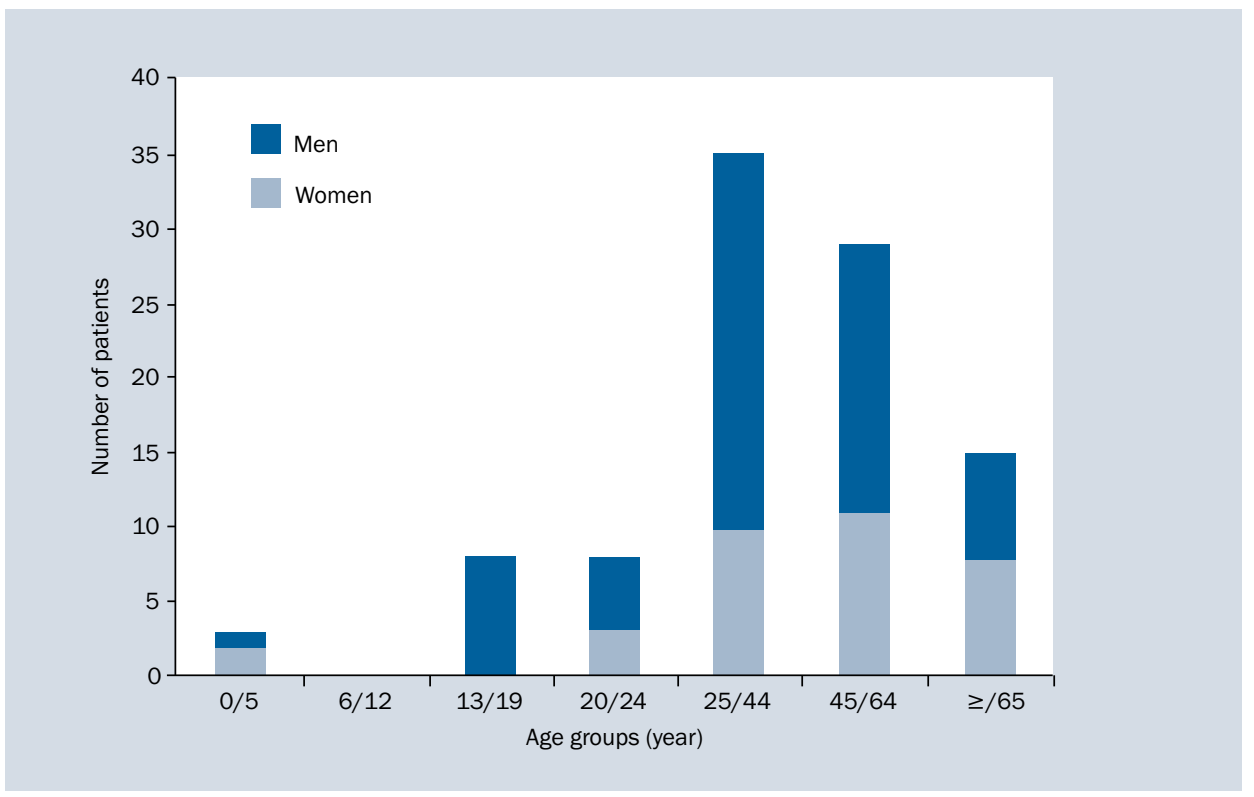

Figure 6. Breakdown of BMPM medical interventions by age groups

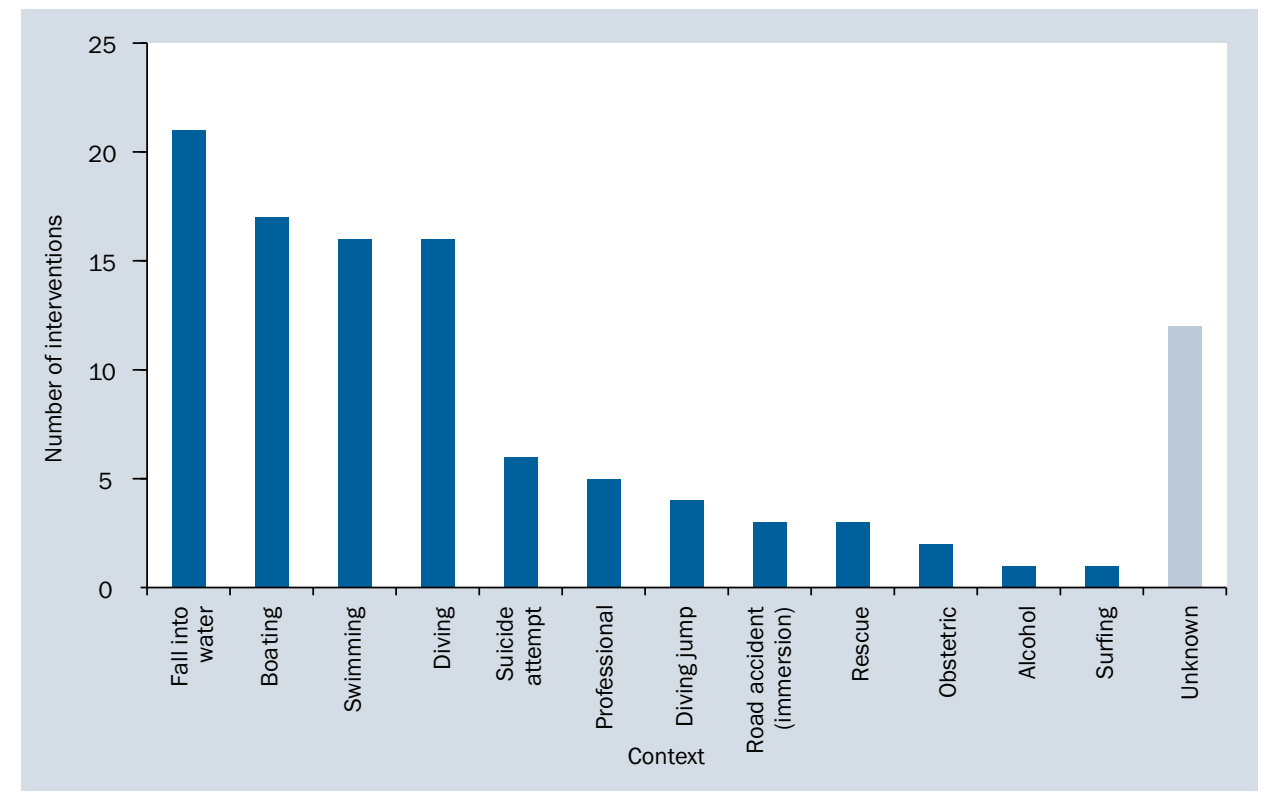

Figure 7. Breakdown of BMPM medical interventions by context

The BMPM's SMURs had an average response time of 15 minutes ( $\mathrm{Cl}$ 95: 10.23; 19.77) ( $n=97)$. Regarding transport, $53 \%$ of patients were cared for by a physician, compared to $21 \%$ without. Approximately $19 \%$ of patients died during surgery and $4 \%$ of patients were not transported to a hospital. The average time from call to arrival at the destination for medical transport was 83 minutes ( $\mathrm{Cl}$ 95: 75.65; 93.35), (101 $\mathrm{min}>300 \mathrm{~m}$ and $78<300 \mathrm{~m}$ ).

A total of 78 patients were transported to the emergency departments (ED) $(n=49)$, intensive care unit (ICU) $(n=17)$, hyperbaric chamber $(n=4)$, cardiology $(n=3)$ or other services $(n=3)$. Circumstantial pathologies constituted $50 \%$ of SMUR diagnoses, followed by traumatic pathologies (23\%).

Concerning circumstantial pathologies: 36 were drownings, 15 were diving accidents, and 2 suffered from hypothermia.

\section{Drowning}

Referring to FIM, 36 drowning victims had SMUR reinforcement from the BMPM, including 14 stages 6 and 5 deaths from the Szpilman classification [1] (Fig. 9). 


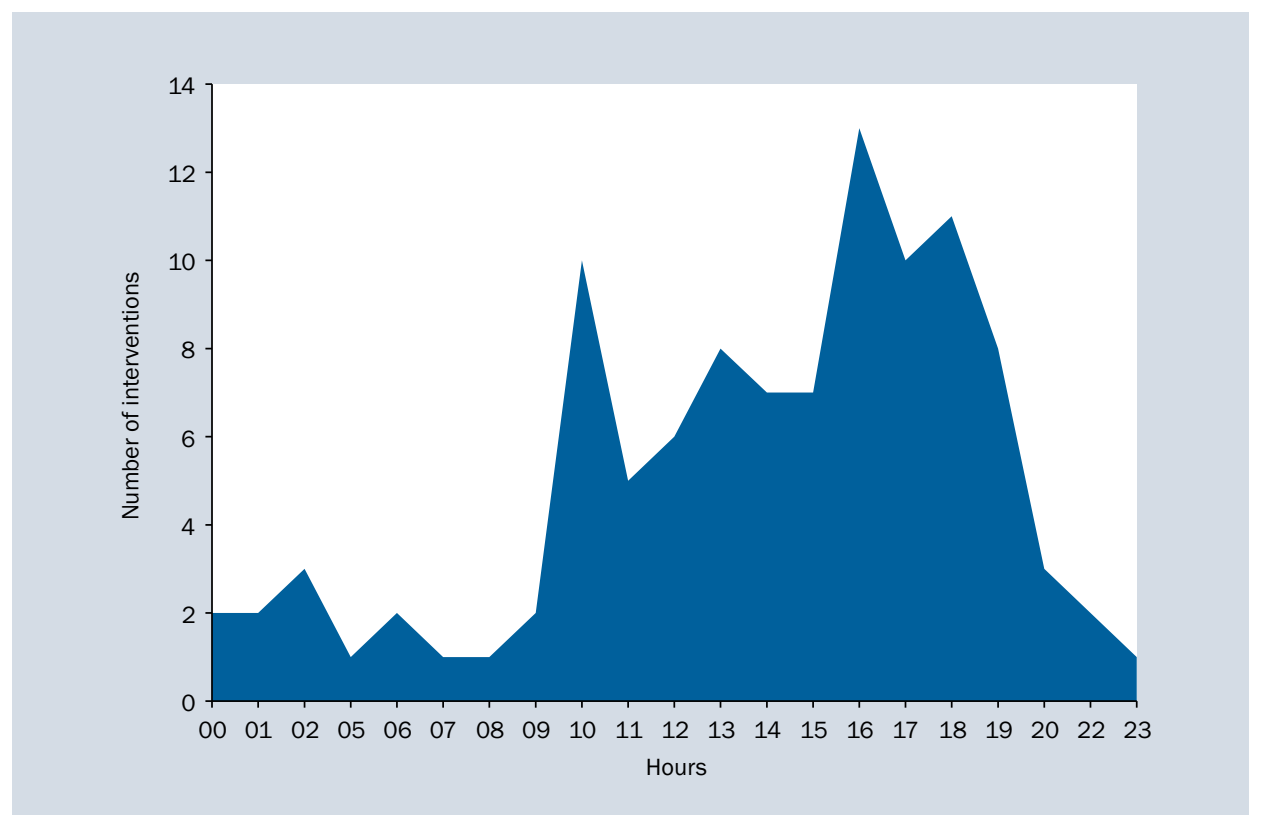

Figure 8. Time allocation of medical interventions of the BMPM

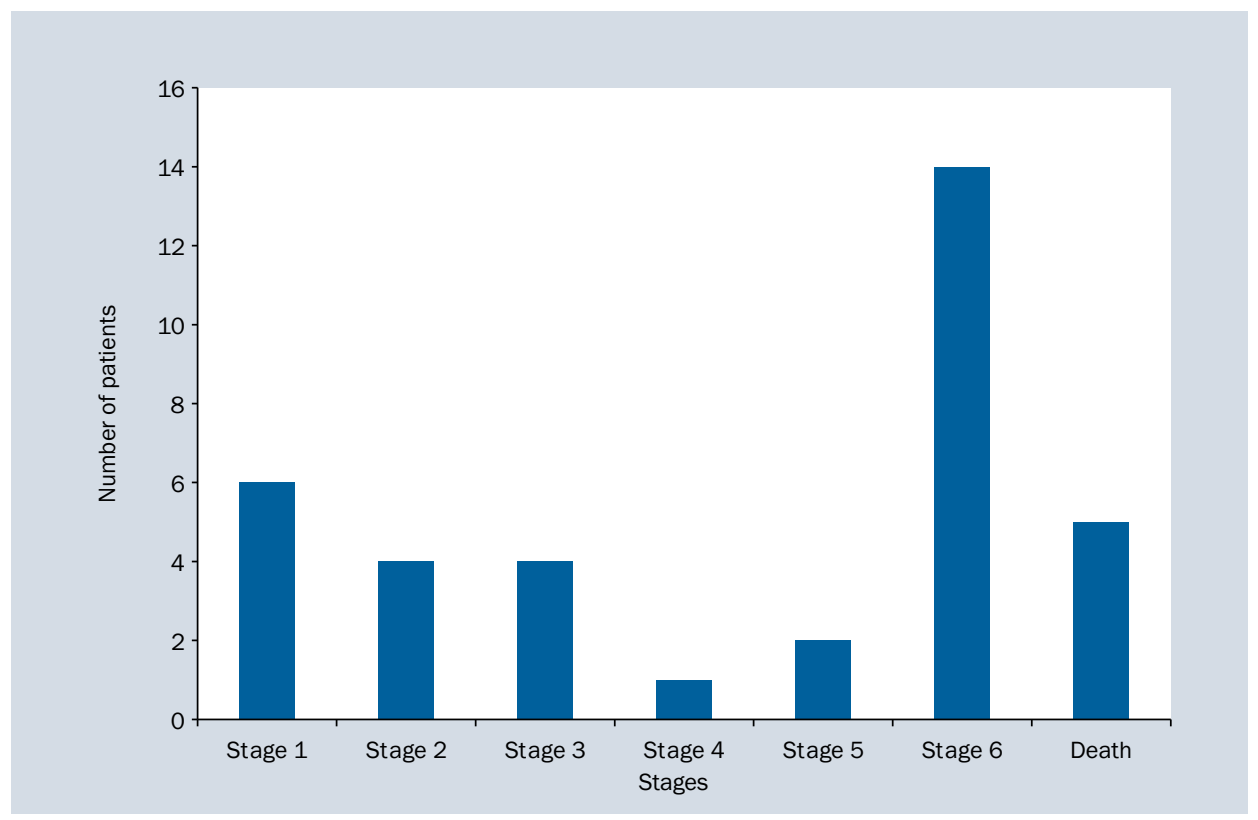

Figure 9. Breakdown of drowning according to Szpilman classification

The breakdown by sex was 56\% male, 39\% female and $6 \%$ unspecified.

The average age of patients by drowning $(n=30)$ was 42 years old ( $\mathrm{Cl} 95$ : 34.36; 49.64; 3-76), 44 years old ( $\mathrm{Cl} 95$ : $31.3 ; 49.64$ ) for women and 40 years old ( $\mathrm{Cl} 95: 30.63 ; 49.37$ ) for men. Nine patients that drowned were between the ages 25 to 44,7 drowned between the ages 45 to 64,6 drowned aged over 65,4 drowned between the ages 13 to 19,3 drowned between the ages 20 to 24, and 1 infant under the age of 5 . The 45-64 year old age group was the most severely affected with 5 stage 6 and 1 death according to Szpilman classification. Only 1 child under 5 years old was recorded (Stage 6).

The majority of drownings occurred in the $300 \mathrm{~m}$ band $(n=29)$.

Pertaining to documented management, $72 \%$ of the drowned patients received oxygen therapy, 36\% intubation, 
$8 \%$ rapid sequence induction (RSI), 31\% had cardiopulmonary resuscitation (CPR) without delivered shock, $6 \%$ received non-invasive ventilation (NIV) and no use of ultrasound was noted in the intervention forms.

Regarding transport, $57 \%$ of patients were transported by a SMUR, $43 \%$ were reported deceased on site and $20 \%$ were transported without a physician. Over $50 \%$ of all transported patients were referred to the ED and ICU.

\section{The diving accident}

Based on the FIM, 15 diving accidents received BMPM'S SMURs support between 2005 and 2017, 7 women and 8 men.

The average age of diving accidents was 44 years ( $\mathrm{Cl} 95$ : 40.23; 55.77), 48 years ( $\mathrm{Cl} 95: 40.23 ; 55.77$ ) for women, 41 years ( $\mathrm{Cl} 95: 33.3 ; 48.7)$ for men. The age distribution by age group included 8 divers aged between 25 and 44 years, 6 divers between 45 and 64 and 1 diver aged over 65 .

The maximum average dive depth was $35 \mathrm{~m}($ IC95 $=8.6)$ for an average dive time of $15 \mathrm{~min}($ IC95 $=10.8)$

Concerning the documented treatments, all divers received hydration, $80 \%$ by VVP, $73 \%$ of patients received oxygen therapy, $40 \%$ acetylsalicylic acid, $27 \%$ orotracheal intubation, $7 \%$ RSI, 20\% CPR, $7 \%$ NIV and $7 \%$ received a delivered shock.

Concerning transport, $54 \%$ of the divers were transported under the supervision of a doctor, $33 \%$ without a doctor and $13 \%$ were declared deceased on site. $47 \%$ of divers were transported to the ED, $27 \%$ to the hyperbaric chamber and $13 \%$ to ICU.

\section{Traumatology}

The FIM analysis identified 24 trauma patients, 18 males and 6 females. The average age was 29 years (15-60), 43 years (30-60) for women and 26 years (15-52) for men. Four age groups were represented: $25-44$ years $(n=7), 45-64$ years $(n=6), 13-19$ years $(n=4)$ and $20-24$ years $(n=2)$.

Trauma-related activities included: power boating $(n=7)$, accidental falls into the water $(n=6)$, sailing $(n=5)$, diving $(n=4)$, road accidents with immersion $(n=1)$ and rescue $(n=1)$.

Pre-hospital diagnoses of patients included 5 severe traumas, 5 shoulder dislocations, 4 whiplash injuries ( 2 with cardiac-circulatory arrest), 2 chest injuries, 2 head injuries, 2 thoracolumbar spinal injuries, 1 traumatic pneumothorax, 1 femoral fracture, 1 thigh injury, and 1 with injury with minor bruises.

Out of the 23 patients that were transported, 20 were monitored by a physician as compared to 3 not needing intervention by a physician. The majority of patients were admitted to the ED $(n=20)$ and 3 patients were admitted directly to the ICU.

\section{DISCUSSION}

The purpose of the study was a descriptive analysis of the BMPM's medical interventions from 2005 to 2017.

The annual number of marine interventions by the BMPM was lower than in other specialized marine rescue structures [2, 3]. The BMPM's rescue activity was not exclusive to the sea and its area of responsibility was geographically limited. The number of interventions requiring a physician increased in contrast to those that did not. There were an increased number of interventions in the summer with a peak frequency in August [2, 4]. The peak in medical interventions between 4 p.m. and 6 p.m. was correlated with peak times in attendance.

The presence of a physician in $8 \%$ of marine interventions was similar to the terrestrial environment (BMPM data).

Nearly 2/3rds of interventions in the maritime environment are carried out in the sector of the southern harbour of Marseille and the Frioul, If and Planier islands. This sector, easily accessible from the city, is concentrated in many activities related to as marine environment (yachting, sailing schools, surfing area, diving activity, beaches, etc...). This observation also explains why SMUR Louvain, Endoume and the VMS "pointe rouge" (local connecting bases) are the most involved in sea-related interventions. The frequency of interventions in the $300 \mathrm{~m}$ band $(77 \%)$ coincides on that recorded by the SCMM Toulon (70\%, summer season 2014).

The average delay time upon arrival on the spot was 15 minutes, which was correlated with the time in town (source SMUR of the BMPM). This can be explained by the vast majority of interventions that were carried out near the shore. The average delay time upon arrival to the hospital was 83 minutes (78 min in the $300 \mathrm{~m}$ band and $101 \mathrm{~min}$ beyond). This delay time could be due to many factors associated with an intervention at sea such as climate, small rescue boats and could be explained by complex evacuations. However it remains below some studies due to the proximity to the shore $[5,6]$.

The most common aetiologies of trauma were accidental fall into the water, boating accidents, swimming, diving, and surfing accidents. The incidence of these accidents can be prevented with increased preventive measures such as compliance with regulations, display of information panels, and dissemination of prevention messages before summer activities.

The analysis of the FIM showed that circumstantial and trauma based accidents were the most common pre-hospital diagnoses found, accounting for $73 \%$. According to the 2015 INVS drowning report, the majority of drownings occurred in the $300 \mathrm{~m}$ range.

Drowning was the leading cause of mortality (57\%) managed by the BMPM SMUR (58.3\% stage 5, 6 and death of Szpilman). This severity is observed in other studies [4, 7-9]. 
While adults between ages 45 and 64 were the most commonly affected, the one infant (under age 5) that drowned was also a Szpilman stage 6 [1]. These results can be interpreted by an erroneous sense of control of the hazards of the maritime environment increasing with age, cardiovascular risk factors, and vulnerability of younger people $[4,10]$.

The management of drowned patients included intubation (36\%), CPR (31\%), and only one NIV was established (on 4 stages 3 of Szpilman) without any documented ultrasound.

The use of the Szpilman classification and ultrasound seems to be a way of improving the management of drowned persons by the BMPM SMURs, as demonstrated in the study by Michelet et al. [11]. The significant rate of CPR and intubation that can be performed under sometimes difficult conditions supports the interest of exercises in exceptional situations and the probable interest of using a message board in a difficult and isolated environment. While the duration of submersion is an essential prognostic factor [12], this parameter is rarely found on FIM. The same applies to associated factors such as alcohol use (INVS drowning survey 2012 and 2015). Finally, prevention remains at the heart of public health issues $[1,10,13]$.

Diving accidents, the second most common cause of circumstantial pathology, accounting for $28 \%$, predominately affected patients over the age of 25. While the depth and duration of dives are systematically recorded, the type of dive, the gas mixtures used, and the number of stops were not frequently recorded on the FIM [14]. All divers received hydration. Of hydration treatment administered, $80 \%$ was by IV, and $73 \%$ of divers received oxygen therapy. $31 \%$ of patients were transported to hyperbaric units and $15 \%$ to the ICU. Investing in further education for BMPM medical teams on the main principles of diving accident management would make it possible to better document the key points of this pathology.

Finally, trauma represented $22 \%$ of the interventions requiring a physician's attention with the BMPM. Nearly $83 \%$ of patients were transported to a local hospital for medical care and $25 \%$ were diagnosed with multiple traumatic injuries. Boating, accidental falls, and diving were the most common high-risk activities. Evaluation of necessary regulations, with a focus on prevention on the dangers of certain maritime activities, must be continued and further strengthened.

\section{STUDY LIMITATIONS}

The retrospective, monocentric nature of the study, located in the municipality of Marseille and the surrounding areas, did not allow the results to be encompassing to the entire French coastline. The heterogeneity of the quality of FIM data entry and loss of partial FIMs, made it possible to identify trends on the variables studied.

\section{CONCLUSIONS}

The BMPM carried out a total of 2375 marine interventions between the years of 2005 to 2017 . The presence of a physician was necessary on 186 occasions. The extraction and analysis of the 107 medical intervention forms found in the BMPM archives revealed a concentration of $67 \%$ of physician intervention in the southern harbour of Marseille and the islands of Frioul, If and Planier. $77 \%$ of interventions took place in the $300 \mathrm{~m}$ band. Accidental falls into the water were the most frequent cause of intervention requiring a physician, followed by boating (sailing and motor), and swimming. Drowning was the most frequent pathology requiring a physician making up 34\% of all interventions. The potential areas for improvement in the management of drowned patients are the use of the Szpilman classification, ultrasound, and non-invasive ventilation. Diving accidents represented $14 \%$ of missions requiring a physician. A reorientation of the training of BMPM physicians on the clinical management of diving accidents would help to optimize the entry of information on FIM. Trauma affected $22 \%$ of the study population and $83 \%$ of trauma patients were transported to hospital for medical care. Accident prevention plans and actions should be continued and reinforced in regards to water sports, diving, and recreational swimming. The increase in maritime traffic and the current international security situations requires that the skills of UMIMM personnel be strengthened and maintained.

The authors of this study have declared they have no competing or secondary interests in relation to this study.

\section{ACKNOWLEDGEMENTS}

Mrs. Melissa Renee Faulk, Physician assistant certified in Tampa (Florida) has participated to the work by controlling the English language.

\section{CONFLICT OF INTEREST}

The authors declare that they have no conflicts of interest in connection with the study.

\section{REFERENCES}

1. Szpilman D, Bierens JJ, Handley AJ, et al. Drowning. N Engl J Med. 2012; 366(22): 2102-2110, doi: 10.1056/NEJMra1013317, indexed in Pubmed: 22646632.

2. Erasmus E, Robertson C, van Hoving DJ. The epidemiology of operations performed by the National Sea Rescue Institute of South Africa over a 5-year period. Int Marit Health. 2018; 69(1): 1-7, doi: 10.5603/IMH.2018.0001, indexed in Pubmed: 29611607.

3. Vinsonneau $\mathrm{U}$, Cavel $\mathrm{C}$, Bombert $\mathrm{C}$, et al. An example of extreme cardiology: chest pain on the high seas and helicoptered medical evacuations: the French Navy experience. Am J Emerg Med. 2012; 30(8): 1591-1596, doi: 10.1016/j.ajem.2011.10.013, indexed in Pubmed: 22205005.

4. Son KL, Hwang SuK, Choi HJ. Clinical features and prognostic factors in drowning children: a regional experience. Korean J Pediatr. 
2016; 59(5): 212-217, doi: 10.3345/kjp.2016.59.5.212, indexed in Pubmed: 27279885.

5. Vinsonneau U. Sauvetage en haute mer et urgences cardiologiques. Archives des Maladies du Coeur et des Vaisseaux - Pratique. 2006; 2006(152): 17-20, doi: 10.1016/s1261-694x(06)78660-6.

6. Leyral J, Quilici J, Meyran D, et al. Prise en charge préhospitali re de I'infarctus du myocarde. Les résultats du registre EPECIM. Journal Européen des Urgences. 2007; 20(3): 113-119, doi: 10.1016/j. jeur.2007.09.001.

7. Bessereau J, Fournier N, Mokhtari T, et al. Epidemiology of unintentional drowning in a metropolis of the French Mediterranean coast: a retrospective analysis (2000-2011). Int J Inj Contr Saf Promot. 2016; 23(3): 317-322, doi: 10.1080/17457300.2015.1047862, indexed in Pubmed: 26082429.

8. Schilling UM, Bortolin M. Drowning. Minerva Anestesiol. 2012; 78(1): 69-77, indexed in Pubmed: 21623341.

9. Hubert $\mathrm{H}$, Escutnaire J, Michelet $\mathrm{P}$, et al. on behalf GR-RéAC. Can we identify termination of resuscitation criteria in cardiac arrest due to drowning: results from the French national out-of-hospital cardiac arrest registry. J Eval Clin Pract. 2016; 22(6): 924-931, doi: 10.1111/jep.12562, indexed in Pubmed: 27292052.

10. Zhu Y, Xu G, Li H, et al. Epidemiology and risk factors for nonfatal drowning in the migrant children. Southeast Asian J Trop Med Public Health. 2015; 46(6): 1112-1123, indexed in Pubmed: 26867370.

11. Michelet $P$, Bouzana $F$, Charmensat $O$, et al. Acute respiratory failure after drowning: a retrospective multicenter survey. Eur $\mathrm{J}$ Emerg Med. 2017; 24(4): 295-300, doi: 10.1097/MEJ.0000000000000362, indexed in Pubmed: 26684548.

12. Quan L, Bierens JJ, Lis R, et al. Predicting outcome of drowning at the scene: A systematic review and meta-analyses. Resuscitation. 2016; 104: 63-75, doi: 10.1016/j.resuscitation.2016.04.006, indexed in Pubmed: 27154004.

13. Layon AJ, Modell JH. Drowning: Update 2009. Anesthesiology. 2009; 110(6): 1390-1401, doi: 10.1097/ALN.0b013e3181a4c3b8, indexed in Pubmed: 19417599.

14. SFMU, SAMU et Urgences de France. Référentiel " Aide médicale en mer ". 2013 nov p. ; 27-36. 